DOI 10.17805/zpu.2018.4.18

\title{
Образ Старика в елизаветинской драме: от персонажа римской трагедии к христианскому Старцу
}

\author{
Н. Э. МИКЕЛАДЗЕ
}

МОСКОВСКИЙ ГОСУДАРСТВЕННЫЙ УНИВЕРСИТЕТ ИМ. М. В. ЛОМОНОСОВА

Трансформация амплуа старого человека в елизаветинской драме рубежа XVI-XVII вв. указывает на возрастание религиозной семантики и аллегоризма. Тема важна и потому, что роли старцев мог играть на сцене актер по имени Уильям Шекспир.

Старик в «Испанской трагедии» Т. Кида еще восходит к сенекианской модели Senex (фигуры «ошибки» в узнавании), но наделяется и новыми чертами родительской любви и достоинства скорби. Доминантой характера Старика в «Фаусте» К. Марло уже является сила веры, он выступает в функции назидания-предостережения незадолго до финала. Сам образ заимствован Марло из Народной книги и имеет реальные прототипы. Старики У. Шекспира - третья модель, в ряде черт наследующая Киду и Марло, но обладающая собственным смыслом и выразительностью.

У шекспировского Old Man выявляются два главных новозаветных архетипа: 1) благочестивый старец Иосиф Плотник (образец трудолюбия, отеческой любви, заботы, верности и веры), к нему восходят Адам в комедии «Как вам это понравится» и Старик в «Короле Лире» и 2) праведный старец Симеон, к которому восходит Старик в «Макбете». Этот персонаж Шекспира очень близок к древнехристианскому пониманию старчества как воплощения аскетической, водительской и пророческой традиций.

Текст доклада автора на Первой Всероссийской научной конференции «Кристофер Марло и его творчество в русской и мировой культуре: междисциплинарный взгляд», которая прошла в Москве 22-23 июня 2018 г.

Ключевые слова: образ Старика; У. Шекспир; К. Марло; Мартин Лютер; Иосиф Плотник; старец Симеон; мистерии; аллегоризм; амплуа; история английской литературы

\section{ВВЕАЕНИЕ}

A нглийская ренессансная драма на этапе становления многими своими особенностями была обязана влиянию римской трагедии Сенеки: сюжеты кровавой мести и рока, призраки и хор, стихомифия и длинные рассказы, риторичность и система твердых амплуа. Однако к концу 1580-х годов оно постепенно рассеивается, уступает другим тенденциям. Елизаветинская драма и театр в эти годы во многом освобождаются от старого канона и встают на самостоятельный путь, который приведет к высочайшему расцвету рубежа XVI-XVII вв. В том числе драматурги-елизаветинцы переосмысливают и преобразовывают образную систему, унаследованную от предшественников. Настоящее исследование, сосредоточенное на одном, казалось бы, второстепенном образе, поможет нам выявить основное направление этих изменений.

\section{ЧЕРТЫ АМПАУА, \\ ВЫРАБОТАННЫЕ В ТРАГЕАИИ СЕНЕКИ}

В трагедиях Сенеки Старик (Senex) был довольно устойчивым персонажем. Он был включен в действие как носитель жизненного опыта, охранитель юношей, верный слуга, умеющий молчать. Но самое главное, функционально Старик оказывался важным, хотя и случайным, звеном в узнавании (anagnorisis, см.: Аристотель, 1998: 1080) и разрешении конфликта. Стоит ли напоминать, что конфликт в трагедии Сенеки неизменно разрешается безоговорочным триумфом Рока, а узнавание состоит в открытии человеком неотвратимости Судьбы. 
В кульминации «Троянок» Сенеки Андромаха, которая пыталась отвести злую судьбу от сына, спрятав его в погребальном холме мужа, вдруг в ужасе и смятении принимала сопровождавшего ее Старика за призрак Гектора, и это заставляло ее совершить ошибку - выдать убежище Астианакса и тем обречь его на смерть.

В трагедии «Эдип» Старик оказывался невольным разоблачителем правды о происхождении героя. Старик появлялся нежданно, и в разговоре с ним Эдип узнавал, что ошибался, считая правителей Коринфа своими родителями. Очная ставка Старика с пастухами открывала герою, что злополучным младенцем с распухшими ступнями, убийцей отца и мужем матери был он сам.

Таким образом, Старик выступает в трагедиях Сенеки прежде всего как безликий голос и инструмент Судьбы:

Пускай сама собой судьба откроется

(Эдип, 832. Пер. С. А. Ошерова; Сенека, 1983: 92). Бог, даже и захочет, так не сыщет бед

(Троянки, 429. Пер. С. А. Ошерова; там же: 244).

Как видно, фигура Старика у Сенеки сопряжена не только с Судьбой и узнаванием, но и с категорией ошибки (hamartia, см.: Аристотель, 1998: 1082): его присутствие либо приводит к ошибке, либо раскрывает ее.

\section{SЕNЕХ В «ИСПАНСКОЙ ТРАГЕАИИ» Т. КИАА}

K этой сенекианской модели в главном восходит Старик (Senex, так на латыни он фигурирует в перечне действующих лиц) в «Испанской трагедии» (ок. 1587) Томаса Кида (1558-1594). Он представляет собой необходимое и случайное звено в узнавании. Он все тот же невольник трагического действия: как тряпичная кукла, от которой, впрочем, может вспыхнуть большой пожар. Само его присутствие на сцене приближает исполнение судьбы и указывает, что она неотвратима. Иными словами, человек есть «подданный судьбы» (“subject to destiny” III, 15, 28; Kyd, 1996: 108).

В «Испанской трагедии» Кид вводит персонаж Старик в эпизоде встречи Иеронимо с просителями (акт III, сц. 13). Эта сцена удваивает кульминацию, обращая ее в два этапа принятия протагонистом решения о мести: этап слова и этап действия. В монологе «Мне отмщение!» (III, 13, 1-44) Иеронимо приходит к этому выбору путем рассуждений, кажущихся ему логическими. В идущем следом эпизоде со Стариком происходит окончательный перелом в настроении Иеронимо. Только когда в горестном помрачении герой принимает Старика за призрак своего убитого сына Горацио, который стыдит его за промедление, - лишь тогда он окончательно утверждается в намерении отмстить убийцам.

Заметим, образ Старика двойственен у Кида: он воплощение родительской любви и неподдельного горя - и при этом фигура «ошибки» (как у Сенеки).

Ааже внешний облик Старика для Иеронимо - «живой образ» его собственных «скорбей»:

\footnotetext{
Живой ты образ горестей моих,

В тебе читаю я свою печаль.

Твои глаза красны, а щеки впали,

Чело нахмурено, твердят уста

Бессвязные обрывки грустных слов, Порывом ветра излетают вздохи,
} 
Всего того причиною твой сын.

Мне причиняет ту же боль мой сын

(III, 13, 162-169; пер. М. М. Савченко; Кид, 2011: 96).

Пристыженный видом убеленного сединами дряхлого старца, непреклонного в своем желании покарать убийц сына, Иеронимо произносил пронзительный монолог:

Смотри, Иеронимо, смотри, стыдясь,

Смотри, как любит отпрыска отец!

Ты видишь стоны и потоки слез,

Которыми, скорбя, исходит он?

Коль такова любовь людей простых,

Коль селится она в умах слабей,

Коль дарит силой немощных она...

...Иеронимо!

Не стыдно ли тебе, что медлишь ты

С отмщеньем за Горацио твоего?

(III, 13, 95-107; там же: 93).

Однако именно видение Горацио, воспринятое как призыв потусторонних сил, обращало Иеронимо на путь личной мести. Следовательно, роковой выбор героя Кида тоже был обусловлен ошибкой, сопряженной с фигурой Старика.

Горацио, так из бездны ты восстал,

Чтоб здесь о справедливости молить?

Чтоб о расплате мне напоминать...

...Не сын? Так, значит, адов демон ты

И послан из пределов черной ночи

За мною. Справедливый Радамант

С Миносом мрачным в ад меня зовут,

Виденья насылая на меня,

Поскольку я за сына смерть не мщу

(III, 13, 133-135, 153-158; там же: 95).

Парадокс состоял и в том, что Старик в «Испанской трагедии» приходил к маршалу (т. е. судье) Иеронимо просить законного наказания убийцам сына. Но галлюцинация с призраком Горацио и неверие судьи в земное правосудие (см. акт III, сц. 12) приводили к противоположному результату: в следующий раз Иеронимо выходил на сцену уже коварным мстителем, режиссером будущего кровавого спектакля.

Следовательно, образ Старика в пьесе Кида опирался в целом на сенекианскую модель (инструмент судъбъ и причина ошибки), но был дополнен такими чертами, как сила духа и достоинство родительской любви и скорби.

\section{СТАРИК В ПЬЕСЕ К. МАРАО - ПЕРВЫЙ САОМ ПАРАДИГМЫ}

Альтернативная модель Старика (Old Man) появляется у Кристофера Марло (1564-1593) в «Трагической истории доктора Фауста» (1589-1592?). Каковы ее особенности?

В пьесе Марло (текст «А», кварто 1604 г.) Старик выходит на сцену незадолго до финала, отводит Фауста от самоубийства, увещевает его сердечно покаяться в грехах и уповать на Божье милосердие. И не без успеха: после встречи со Стариком в душе героя «ад борется с молитвой» (“Hell strives with grace for conquest"; Marlowe, 1910: 
39). Так что Мефистофель даже требует от него повторного заключения договора

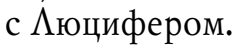

Старик - не самостоятельное детище драматурга, а заимствование. Марло переносит в свою пьесу образ Старика из народной книги «История о докторе Иоганне Фаусте, знаменитом чародее и чернокнижнике» в издании Шписа (1587) (далее - Народная книга) (Иегенда ..., 1978: 35-119). Тот, в свою очередь, был собран из нескольких благочестивых старцев, описанных в исторических источниках немецкой легенды о Фаусте. Таков монах Клинг из «Эрфуртской хроники» («увещевал его добром», «грозил карой Божией», убеждал, что Фауст может «отмолить у Бога... прощение») (там же: 31-32). Это и сподвижник ученика Августина ерхеймера («отчитал его как следует», призывал «отступиться от нечестивых дел», не испугался угроз и магии) (там же: 22-23). Наконец, это старый молитвенник из «Застольных бесед» Мартина Аютера, образ, почерпнутый «в житиях отцов»:

«Однажды сидел один старец и молился. Аьявол же стал преследовать его и поднял такой шум, что показалось старцу, будто слышит он визг и хрюканье целого стада свиней: цо! цо! цо! Этим дьявол думал его напугать и помешать молитве. Тогда старец заговорил и сказал: “Эй, дьявол, поделом тебе случилось; был бы ты прекрасным ангелом, а теперь ты стал свиньей”. Тут сразу же прекратились визг и хрюканье. Ибо Аьявол не терпит, когда его поносят» (там же: 17).

Показательно уже то, что при всей тщательности и ограничениях в отборе эпизодов из Народной книги о Фаусте елизаветинский драматург берет в свою трагедию обе сцены со Стариком (главы 52, 53): увещевание Фауста и терзание старца бесами.

Марло даже несколько расширяет характеристику Старика, показывая его глазами служителей зла. Фауст называет его «подлым и бесчестным» ("that base and crooked age"; Marlowe, 1910: 39), a Мефистофель объясняет границы своих возможностей силой Веры этого человека:

His faith is great; I cannot touch his soul

Сильна его бесхитростная вера -

(Marlowe, 1910: 39).

Я не могу души его коснуться,

Но плоть его измучу, как смогу,

Хоть нет цены для ада в этих муках

(Трагическая история..., сц. XIII; пер. Н. Н. Амосовой; Иегенда о докторе Фаусте, 1978: 238).

Это подтверждает вторая сцена с терзаемым демонами Стариком: его вера побеждает ад ("My faith, vile hell, shall triumph over thee"; Marlowe, 1910: 40).

К сказанному сделаем одно важное уточнение. В тексте «В» трагедии Марло (т. е. в кварто 1616 г.) второй сцены со Стариком нет, а его монолог из первой сцены существенно видоизменен: приведен в большее соответствие с проповедью старца Народной книги о вреде волшебства (Иегенда ..., 1978: 89).

Старик в Народной книге появлялся в жизни Фауста на семнадцатом году его сделки, за долгие семь лет до гибели, и был одним из череды эпизодов на пути чернокнижника. У Марло Старик приходит бороться за душу Фауста перед самой развязкой. Аишь исповедь-предупреждение студентам и монолог «Один лишь час тебе осталось жизни» (сцена XIV) отделяют встречу со Стариком от конца песочных лет героя. 
А значит, по замыслу Марло, Старику была доверена решающая попытка отвратить Фауста от зла, направить его на стезю благодати.

Следовательно, Старик выступает в конце истории в той же функции назиданияпредостережения, что и Аобрый Ангел начала пьесы, до подписания Фаустом рокового договора с дьяволом. Однако Старик в трагедии Марло - не чистая аллегория из моралите, а вполне телесный, хотя и схематичный, образ христианского праведника, имеющий даже реальные исторические прототипы.

\section{ШЕКСПИР: ОТ ЭАЕМСКОГО СТАРИКА \\ К ХРИСТИАНСКОМУ СТАРЦУ}

Модель Старика, разрабатываемая Уильямом Шекспиром (1564-1616), - третий путь - в определенном смысле синтезирует варианты Кида и Марло.

Шекспир не свяжет с этим персонажем ${ }^{1}$ ни ошибку, ни прямое назидание, не сделает его инструментом судьбы.

Сила Верь - определяющее свойство, которое унаследуют Старики Шекспира у Марло. Отеческое достоинство, любовь и скорбь свяжут их со Стариком Кида.

Шекспир наделит этот персонаж немногословной мудростью, свойственной как сенекианским, так и библейским старцам, умением отличать добро от зла и свободным выбором.

Старика Адама в комедии «Как вам это понравится» (1599) можно рассматривать как эскиз характера Старика, от которого затем Шекспир будет отсекать лишнее. Адам -

$$
\text { ...пример }
$$

Той честной, верной службы прежних лет,

Когда был долгом труд, а не корыстью

(II, 3; пер. Т. А. Щепкиной-Куперник; Шекспир, 1959: 35).

Адам - садовник, всю жизнь бережно растивший эдемский сад. Он неизменно на стороне добродетели. И хочет быть ей в помощь. Он пытается примирить братьев именем их умершего отца, спасает из западни своего молодого господина, отдает ему последние накопления, готов сопровождать его в скитаниях и «служить до смерти верой, правдой» (II, 3; там же: 35):

Master, go on; and I will follow thee

To the last gasp, with truth and loyalty

(II, 3; Shakespeare, 1994: 619).

В подобном выборе, совершаемом в восемьдесят лет (fourscore), он всецело полагается на Бога:

\section{...Тот, Кто воронов питает \\ И посылает пищу воробью, \\ Мою поддержит старость!}

(II, 3; пер. Т. А. Щепкиной-Куперник; Шекспир, 1959: 34).

И доброму старцу (good old man), который ведом верностью и «чистой любовью» (“in pure love", II, 7; Shakespeare, 1994: 622), воздастся по его делам: Старый Герцог накормит его и позовет быть гостем в своей пещере (II, 7; там же: 623).

Таков старый человек в комедии. Степень обобщения и аллегоризма в образе Старика у Шекспира будут лишь возрастать. 
Bce реплики Старика (Old Man) в трагедии «Король Аир» (1605/06) сосредоточены в начале четвертого действия, когда зло окончательно захлестнуло мир и просвета не видно. Это низшая ступень.

Тогда на сцену и выходит Старик, он ведет ослепленного Глостера.

Этот восьмидесятилетний (fourscore years) Старик всю жизнь был простым арендатором-земледельцем у Глостера, а прежде у его отца. Под угрозой собственной жизни он помогает ему. И дело тут не в верности, а в доброте, помощи ближнему.

Причина проста, Старик объясняет так: кто-то должен показать слепому дорогу (“You cannot see your way"; IV, 1, 17; Shakespeare, 1990: 139). И становится поводырем. Когда Глостер выбирает в поводыри голого нищего безумца (Эдгара), Старик отдает ему свое лучшее платье и уходит со словами:

\section{... И будь что будет}

(“Come on't what will”; IV, 1, 50; Shakespeare, 1990: 141).

Функция Старика в «Короле $\Lambda$ ире» очень важна. Этот Old Man - пример сострадания и помощи страждущему. Ему так же жаль бедного Тома... Аюбви к ближнему не нужно много слов, она может быть показана в краткой зарисовке.

Шекспир постепенно проясняет вызревающую у него модель Старика. Отсекает лишнее. Его Старик не отец, не сын, не слуга, не вассал, руководим не родственными чувствами, не надеждой на награду и даже не благодарностью и преданностью.

Он просто подлинный христианин.

Показательно также, что Старик появляется на сцене как символ перемены $\mathbf{b}$ действии после слов Эдгара:

Плачевна перемена для счастливцев.

Несчастным поворот - на радость...

(IV, 1, 5-6; пер. М. Кузмина; Шекспир, 1990: 263).

И несмотря на весь трагизм грядущего, это перемена к лучшему: отцы соединятся с добрыми детьми, Глостер обретет христианское смирение, Аир прозреет в безумии и преобразится.

Наконец, Старик в «Аире» ухолит со сцены, уповая на Провидение: «Аа будет Твоя воля» (IV, 1, 50). И передает опыт христианского упования Эдгару.

Еще больше фигурой является Старик (Old Man) в «Макбете» (1606), самый выразительный из всех: луч света на фоне опускающийся черной ночи.

Он выходит на подмостки в победный момент торжества зла (акт II, сц. 4). Тодько что совершилось преступление, нарушившее все человеческие и Божьи установления, - святотатственное убийство Аункана. Только что душа убийцы и предателя Макбета перешла во владения князя ада. Только что земную власть попрал вероломный злодей. Только что мир вступил на путь тьмы.

Старик дает ясную характеристику этого перелома: в жизни не было такой больной (sore) ночи; этот мрак противен естеству (unnatural), как само деяние, его породившее; в природе тоже все пошло наоборот... (II, 4, 1-18; Shakespeare, 2016: 197-198).

В трагедии «Макбет» Шекспир выводит Старика в точке апогея, перехода от полноты добра к заполняющему мир злу.

Но Старик верит, что это не конец Божьего мира. И слово надежды отдано драматургом ему. Перед уходом со сцены Старик именем Бога благословляет суровых воинов Макдуфа и Росса в будущем вернуть миру благодать, а людям любовь и доверие: 
God's benison go with you, and with those

That would make good of bad and friends of foes

(II, 4, 40-41; Shakespeare, 2016: 200).

Вера не подведет Старика. В финале трагедии Божье воинство под предводительством Малькольма одержит победу над тираном и освободит мир от власти тьмы.

Следовательно, Старик в «Макбете» сопряжен с сюжетом грядущего: Второго пришествия Христа, Страшного суда и Нового Царства. Сюжетом, который намечен в линии Макдуфа и верных танов.

\section{ВЕРОЯТНЫЕ АРХЕТИПЫ И АРУГИЕ ВЫВОАЫ}

Таким образом, Старики Шекспира - третья модель, возникшая в елизаветинской драме, наследующая в ряде черт Марло и Киду, но обладающая собственной особой семантикой и выразительностью.

1. Old Man освобожден драматургом

а) от прямолинейной назидательности (свойственной Старику в «Фаусте» Марло),

б) от сопряженности с категорией ошибки (отличающей Старика у Кида).

2. Старики Шекспира - простые люди, труженики (садовник, земледелец), прожившие долгую жизнь (70-80-летние), верующие в Бога и конечную победу добра, уповающие на Провидение.

3. Композиционно они - предвестники поворота к лучшему, подъема ("stands still in esperance", IV, 1, 4; Shakespeare, 1990: 137).

4. Персонаж демонстрирует тенденцию к превращению в фигуру средневекового религиозного театра и показывает возрастающую склонность трагедии Шекспира к аллегоризму.

5. У шекспировского Old Man выявляются два главных новозаветных архетипа:

- праведный и благочестивый старец Иосиф Плотник - образец трудолюбия, отеческой любви, заботы, верности и веры (см. его характер в «Книге Иосифа Плот-

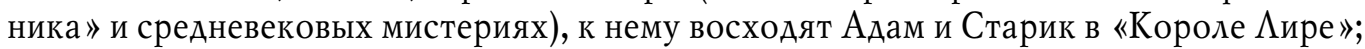

- праведный и благочестивый старец Симеон (см.: Аука 2: 25-35). Старик в «Макбете» восходит именно к нему, благословляющему тех, кто принесет новый мир и благой закон:

\footnotetext{
Я знаю, нас спасенье ждет, И говорю, друзья, о том:

Послал Ты свет, и в свой черед

Он воссияет в мире всем.

О, сколь я рад!

Хвалу, Господь, Тебе пою.

Воссядет праведный в Раю,

А кто грешил всю жизнь свою,

Падет во Ад!
}

(XVIII, 6; пер. В. С. Сергеевой; Мистерии Йоркского цикла, 2014: 243).

Как мы видим, Шекспир знакомит своего зрителя с тремя типами Cтарцев:

- эдемский (Адам безгрешен, чист сердцем, неимущ),

- евангельский (смиренномудрый старец «Короля Аира», водитель слепого),

- Апокалипсиса и Нового Царства (в «Макбете»). 
Этот последний Старец (названный в тексте father) ближе всех к древнехристианскому пониманию старчества как совокупного воплощения аскетической, водительской и пророческой традиций.

\section{NOTA BENE}

Развитие содержания амплуа Старика у елизаветинцев нам важно еще и потому, что роли Стариев мог играть на сцене актер по имени Уильям Шекспир. Согласно сохранившимся свидетельствам, именно он играл старика Адама в комедии «Как вам это понравится» (Шенбаум, 1985: 263-264). В эпоху твердых амплуа это говорит о многом. Подобное предпочтение актера Шекспира вполне согласуется с другими функциями, которые он, очевидно, также исполнял в своей труппе, - автора и постановщика пьес, что практически исключало долгое пребывание на сцене и масштабные роли. Так что ничто не мешает нам представить Шекспира в ролях благородных и человечных Cmapиељ «Макбета» и «Короля Аира». Живых образов надежды.

\section{ПРИМЕЧАНИЕ}

1 у Шекспира мы находим (и рассматриваем в данной статье) лишь три случая изображения старого человека, всецело отвечающие амплуа Старика. Старик (Old Man) всегда является второстепенным персонажем (он не протагонист и не антагонист), немногословным, эпизодическим, безымянным (садовник, названный Адамом, лишь подтверждает это правило). Персонажи, подобные Old Gobbo («Венецианский купец»), Old Athenian («Тимон Афинский»), Old Shepherd («Зимняя сказка»), ограничены отцовской функцией. Они отцы своих детей - молодого Гоббо, молодых афинянина и пастуха - и только. Они не являются фигурами, предполагающими многозначное аллегорическое наполнение. И только в одном 80-летнем герое короле $\Lambda$ ире последних сцен - можно обнаружить также некоторые черты шекспировского Old Man. Они успевают взрасти в этом протагонисте, проходящем свой крестный путь и испытывающем преображение.

\section{СПИСОК АИТЕРАТУРЫ}

Аристотель (1998). Поэтика // Аристотель. Этика. Политика. Риторика. Поэтика. Категории / пер. Н. И. Новосадского. Минск : Аитература. 1391 с. С. 1064-1112.

Кид, Т. (2011) Испанская трагедия / подг. изд. Н. Э. Микеладзе, М. М. Савченко ; пер. М. М. Савченко. М. : Аадомир; Наука. 328 с.

Иегенда о докторе Фаусте (1978) / подг. изд. В. М. Жирмунский. 2-е изд., испр. М. : Наука. 424 с. Мистерии Йоркского цикла (2014) / подг. изд. А. Н. Горбунов, В. С. Сергеева. М. : $\Lambda$ адомир; Наука. 895 с.

Сенека, Ауций Аней (1983) Трагедии / подг. изд. С. А. Ошеров, Е. Г. Рабинович. М. : Наука. 432 c.

Шекспир, У. (1959) Как вам это понравится // Шекспир У. Полное собрание сочинений : в 8 т. / пер. Т. А. Щепкиной-Куперник. М. : Искусство. Т. 5. С. 5-112.

Шекспир, У. (1990) Король Аир / пер. М. Кузмина // Шекспир У. Пьесы в переводе М. Кузмина / ред. А. Н. Горбунов. М. : Московский рабочий. 433 с. С. 151-324.

Шенбаум, С. (1985) Шекспир. Краткая документальная биография / пер. А. А. Аникста и А. $\Lambda$. Величанского. М. : Прогресс. 432 с.

Kyd, T. (1996) The Spanish Tragedy. Ed. by D. Bevington. Manchester UP. 147 p.

Marlowe, C. (1910) The Tragicall History of Doctor Faustus (1604). London : J. M. Dent \& Sons, Ltd., New York : E.P. Dutton \& Co. 44 p.

Shakespeare, W. (1990) King Lear. Ed. by K. Muir. The Arden Shakespeare. L., N. Y. 246 p.

Shakespeare, W. (1994) The Complete Works of William Shakespeare. Ware : Wordsworth Editions. $1263 \mathrm{p}$. 
Shakespeare, W. (2016) Macbeth. Ed. by S. Clark and P. Mason. The Arden Shakespeare. Bloomsbury. 381 p.

Аата поступления: 30.08.2018 2.

\section{IMAGE OF THE OLD MAN IN THE ELIZABETHAN DRAMA: FROM THE ROMAN TRAGIC CHARACTER TO THE CHRISTIAN ELDER \\ N. E. MIKELADZE \\ LOMONOSOV MOSCOW STATE UNIVERSITY}

The ransformation of the character of the Old Man in the Elizabethan drama at the turn of the 17 th century indicates an increase in religious semantics and allegorism. Special value to the subject is added by the fact that the elders role could have been played by the actor named William Shakespeare.

The Old Man in "The Spanish tragedy" by Thomas Kyd still goes back to the Senecian model Senex (the figure of "mistake" in recognition), but is endowed with new features of parental love and the dignity of sorrow. The dominant feature of the Old Man in Christopher Marlowe's "Faust" is already the power of faith, he acts as a warning-edification shortly before the finale. The image itself is borrowed by Marlowe from the folk book and has real prototypes. The Old Men in Shakespeare's plays are the third model, inheriting Kyd and Marlowe to some extent, but possessing its own meaning and expressiveness.

Shakespeare's Old Man reveals two main archetypes rooted in the New Testament: 1) the pious elder Joseph the Carpenter (an example of diligence, fatherly love, care, loyalty and faith), Adam in the comedy "As You Like It" and the Old Man in "King Lear" go back to this model; 2) the righteous Simeon the Elder - prototype for the Old Man in "Macbeth". This Shakespearean character is very close to the ancient Christian understanding of the eldership as the embodiment of ascetic, guiding, and prophetic traditions.

The text of the author's speech at the First All-Russian Scientific Conference "Christopher Marlowe and His Oeuvre in Russian and World Culture: an Interdisciplinary Viewpoint", which was held in Moscow on the 22-23 June 2018.

Keywords: image of the Old Man; W. Shakespeare; C. Marlowe; Martin Luther; Joseph the Carpenter; Simeon the Elder; mystery plays; allegory; theatrical character; history of the English literature

\section{REFERENCES}

Aristotel' (1998) Poetika. In: Aristotel'. Etika. Politika. Ritorika. Poetika. Kategorii / transl. by N. I. Novosadskii. Minsk, Literatura. 1391 p. Pp. 1064-1112. (In Russ.).

Kid, T. (2011) Ispanskaia tragediia / prepared the edition by N. E. Mikeladze and M. M. Savchenko; transl. by M. M. Savchenko. Moscow, Ladomir; Nauka. 328 p. (In Russ.).

Legenda o doktore Fauste (1978) / prepared by V. M. Zhirmunskii. 2-e izd., ispr. Moscow, Nauka. 424 p. (In Russ.).

Misterii Iorkskogo tsikla (2014) / prepared by A. N. Gorbunov and V. S. Sergeeva. Moscow, Ladomir; Nauka. 895 p. (In Russ.).

Seneka, Lutsii Anei (1983) Tragedii / prepared by S. A. Osherov and E. G. Rabinovich. Moscow, Nauka. 432 p. (In Russ.).

Shekspir, U. (1959) Kak vam eto ponravitsia. In: Shekspir U. Polnoe sobranie sochinenii : in 8 vol./ transl. by T. L. Shchepkina-Kupernik. Moscow, Iskusstvo. Vol. 5. Pp. 5-112. (In Russ.).

Shekspir, U. (1990) Korol' Lir / transl. by M. Kuzmina. In: Shekspir U. P'esy v perevode M. Kuzmina / ed. by A. N. Gorbunov. Moscow, Moskovskii rabochii. 433 p. Pp. 151-324. (In Russ.).

Shenbaum, S. (1985) Shekspir. Kratkaia dokumental'naia biografiia / transl. by A. A. Anikst and A. L. Velichanskii. Moscow, Progress. 432 p. (In Russ.).

Kyd, T. (1996) The Spanish Tragedy. Ed. by D. Bevington. Manchester UP. 147 p. 
Marlowe, C. (1910) The Tragicall History of Doctor Faustus (1604). London : J. M. Dent \& Sons, Ltd., New York, E. P. Dutton \& Co. 44 p.

Shakespeare, W. (1990) King Lear. Ed. by K. Muir. The Arden Shakespeare. L., N. Y. 246 p.

Shakespeare, W. (1994) The Complete Works of William Shakespeare. Ware, Wordsworth Editions. 1263 p.

Shakespeare, W. (2016) Macbeth. Ed. by S. Clark and P. Mason. The Arden Shakespeare. Bloomsbury. $381 \mathrm{p}$.

Submission date: 30.08 .2018$.

Микеладзе Наталья Эдуардовна - доктор филологических наук, профессор кафедры зарубежной журналистики и литературы Московского государственного университета им. М. В. Аомоносова. Адрес: 125009, Россия, г. Москва, ул. Моховая, д. 9. Тел.: +7 (495) 629-37-80. Эл. адpec: fornatalia@bk.ru

Mikeladze Natalya Eduardovna, Doctor of Philology, Professor, Department of Foreign Journalism and Literature, Lomonosov Moscow State University. Postal address: 9, Mokhovaya St., Moscow, Russian Federation, 125009. Tel.: +7 (495) 629-37-80. Email: fornatalia@bk.ru

DOI 10.17805/zpu.2018.4.19

\title{
Философ в круге Марло: Уолтер Рэли и его трактат «Рассуждение о первоначальной и фундаментальной причине естественной, произвольной, необходимой и противоестественной войны»
}

\author{
В. В. МАРХИНИН
}

СУРГУТСКИЙ ГОСУДАРСТВЕННЫЙ УНИВЕРСИТЕТ

В статье рассматриваются взгляды Уолтера Рэли (1552-1618), английского политика, военного деятеля, мыслителя и поэта из круга Кристофера Марло. Предметом статьи является концепция войны, выработанная Рэли и сделанная им отправной точкой в анализе динамики общественной жизни в целом.

Рассматривается вопрос о характере возможного влияния социально-философских идей Рэли на мировоззрение Марло, анализируются идеи философских и политических трактатов Рэли, выявляется его место в разработке проблематики войны в философской литературе Ренессанса. Ключевые темы философского творчества Рэли - анализ феноменов войны, политических манипуляций, мотивов политического действия - созвучны сюжетам драматургии Марло, в то же время содержание его рассуждений коренным образом отличается от распространенного в литературе представления о вольнодумстве Марло. Влияние, которое могло испытывать мировоззрение Марло со стороны философских идей Рэли, по нашему мнению, имело направленность, типичную для христианского гуманизма в духе Эразма Роттердамского.

В своем трактате Рэли выступает с антивоенных позиций и стремится выявить предпосылки возникновения войн и условия, необходимые для их предотвращения. Среди войн он выделяет, во-первых, «естественные», связанные с борьбой за обладание жизненно важными ресурсами. Некоторые из них - неизбежны, другие - произвольны и, следова- 